\title{
Detecting vuggy porosity in carbonate reservoirs by well logs
}

\author{
Yousef Asgarinezhad $^{1} \cdot$ Masoud Asgarinezhad $^{2} \cdot$ Behzad Tokhmechi $^{1} \cdot$ \\ Abolghasem Kamkar-Rouhani ${ }^{1} \cdot$ Shahram Sherkati $^{3}$
}

Received: 2 February 2013/Accepted: 12 April 2015/Published online: 5 May 2015

(C) The Author(s) 2015. This article is published with open access at Springerlink.com

\begin{abstract}
Vuggy porosity is a type of porosity in carbonate rocks. This kind of porosity significantly affects the permeability, pressure drop and recovery factor in the reservoir. Therefore, their identification and modeling is important for the reservoir characterization and history matching. Image logs, RCAL and SCAL tests are main tools to determine vugs, though all are costly and sometimes unavailable. Thus, development of a generalized approach to recognize vugs in reservoirs will be significant. In this paper, a combined majority voting-Parzen-wavelet based algorithm is developed using gamma ray (GR), neutron porosity (NPHI), bulk density (RHOB) and sonic (DT) $\operatorname{logs}$ for identification of vugs in frequency domain. The agreement between the core tests results and the results of this newly developed method confirms the application of proposed new method.
\end{abstract}

Yousef Asgarinezhad

nejad8665@yahoo.com

Masoud Asgarinezhad

masoodasgarinejad@yahoo.com

Behzad Tokhmechi

tokhmechi@ut.ac.ir

Abolghasem Kamkar-Rouhani

kamkarr@yahoo.com

Shahram Sherkati

ssherkati@hotmail.com

1 Mining, Petroleum and Geophysical Engineering Faculty, Shahrood University of Technology, Shahrood, Iran

2 Geodesy and Geomantic Engineering Faculty, Khaje nasirAl_din Toosi University, Tehran, Iran

3 Exploration Directorate of National Iranian Oil Company, Tehran, Iran
Keywords Vug - Majority voting - Wavelet - Parzen classifier · Well log · Core test

$\begin{array}{ll}\text { Abbreviations } \\ \text { GR } & \text { Gamma Ray } \\ \text { RHOB } & \text { Bulk density } \\ \text { NPHI } & \text { Neutron porosity } \\ \text { DT } & \text { Sonic } \\ \text { PLs } & \text { Petrophysical logs } \\ \text { MV } & \text { Major Vote } \\ \text { CD1 } & \text { Details 1 } \\ \text { CD2 } & \text { Details 2 } \\ \text { CD3 } & \text { Details 3 } \\ \text { CA1 } & \text { Approximate 1 } \\ \text { CA2 } & \text { Approximate 2 } \\ \text { CA3 } & \text { Approximate } 3\end{array}$

\section{Introduction}

Identifying vuggy zones is one of the key issues in carbonate reservoir characterization. Vugs plays an important role in reservoir quality, storage capacity and flow properties of porous space, and can be found in two classes: separate vugs and touching vugs (Lucia 1983; Perez-Rosales et al. 2002). In general, the productivity of a reservoir will increase where the fractures are decreasing and the touching vugs are expected (Akram et al. 2010).

Vuggy fractured reservoirs are one of the most important types of oil production reservoirs. For high effect of reliable analytical formulations on storage capacity, geometrical properties, and flow properties of porous space, these formulations have been developed (Perez- 
Rosales et al. 2002). Vugs can be defined as visible pores that are significantly larger than adjacent grains or crystals. (Lucia 1983). Aguilera for dual porosity systems suggested several equations which is valid in combinations of matrix and fractures or non-connected vugs (Aguilera 2008). The productivity will increase where the fractures are decreasing and the touching vugs are expected (Akram et al. 2010). After studying electrical responses and comparison between the homogeneous and vuggy porosity models, we can find at constant frequency, a difference between the two respective saturation exponents (Pairoys et al. 2012).

Gomaa et al. introduced another definition of vugs as pore throats larger than 5 microns in diameter through mercury injection capillary pressure studies (Gomaa et al. 2006). They also classified another type of the pores as vugs which are larger than approximately 50 microns filled with water or light oil and can be detected by NMR log (Gomaa et al. 2006).

There are three reasons in the difficulty of facies modeling and prediction from well logs as follows: (1) the complexity of carbonate facies structures, (2) strong diagenetic overprinting, and (3) challenging log analysis due to presence of vugs and fractures (Tang et al. 2009). Using the general method described by Hurley, Vug fraction was quantified from the core slabs (Hurley et al. 1998). Visual descriptions of core showed dimensions of individual vugs vary ranging from $2-3 \mathrm{~mm}$ to $2 \mathrm{~cm}$ (Pinous et al. 2007). In 1962, Towle considered some assumed pore geometries as well as tortuosity, and noticed a variation in the porosity exponent $\mathrm{m}$ in Archie's equation ranging from 2.67 to $7.3+$ for vuggy reservoirs, and values much smaller than two for fractured reservoirs. Matrix porosity of Towle's models is considered as zero (Towle 1962). The previous studies on detecting vuggy porosities include: a study by Aguilera and Aguilera on carbonate reservoirs by triple porosity model which are composed of mainly matrix, fractures and non-connected vugs using petrophysical evaluation (Aguilera and Aguilera 2004) developing an expression for the formation resistivity factor of vuggy fractured media in terms of fracture and vug porosities (Perez-Rosales et al. 2002).
During the past years, several works have also been carried out to identify carbonates pore type from well logs (Mengual 2000; Asgarinezhad et al. 2014; Mollajan et al. 2014).

In this paper, a data driven approach is presented to detect vuggy zones using petrophysical logs. The performance of the proposed algorithm is verified through comparing with core data.

\section{Data}

To examine the efficiency of the proposed algorithm, we used data related to two different oil fields-two wells from field $\mathrm{A}$ and the remaining four wells from field $\mathrm{B}$. From geological point of view, the studied reservoirs are placed in carbonate formations in west of Iran.

The available well logs include: GR, DT, NPHI and RHOB, as well as complete reports of core studies to verify the results. The input data of this study are shown in Table 1.

\section{Methodology}

In this study, majority voting (MV) as commonly used data fusion algorithm has been employed to combine the results of generalization step. The following section, briefly describes the MV algorithm.

\section{Majority voting (MV) data fusion}

If the domain of the measured property is finite, voting methods can be applied to fuse several sensor values. Voting methods are often used in fault-tolerant systems (Ghosh et al. 2010). This method can be rendered as the oldest and the most well-known method within all decision making strategies. This method can only be used as a fusing tool for integrating outputs of other classifiers that have clear labels on the output data.

Table 1 The selected input data

\begin{tabular}{|c|c|c|c|c|c|c|}
\hline Wells & W1 & $\mathrm{W} 2$ & W3 & W4 & W5 & W6 \\
\hline \multirow[t]{2}{*}{ Depth (m) } & 1717.08 & 1657.01 & 1193.9 & 914.25 & 3333.14 & 3382.36 \\
\hline & -2132.98 & -1808.13 & -1344.5 & -1116.94 & -3380.38 & -3470.60 \\
\hline Formation & Sarvak & Illam & Sarvak & Illam & Illam & Sarvak \\
\hline Field no. & A & A & A & A & B & B \\
\hline Utilized loges & All & No DT & All & All & All & All \\
\hline Availability of cores & Yes & Yes & Yes & Yes & Yes & Yes \\
\hline
\end{tabular}


Consider the outputs of each classifier being binary in $\mathrm{c}$ dimensions ( $\mathrm{c}$ is the number of classes):

$\left[d_{i, 1}, d_{i, 2}, \ldots, d_{i, c}\right]^{T} \in\{0,1\}$

where $i=1 \ldots L, j=1 \ldots c$ and $d_{i j}=1$ if and only if the data, $x$ belongs to the class $j$. Otherwise, $d_{i j}$ will be zero. Then, MV is simply summation of $d_{i j}$ values as:

$\operatorname{Max}_{j=1}^{c}\left(\sum_{i=1}^{L} d_{i, j}\right)$

It means that $x$ belongs to the $k$, whereas ... is the maximum if $j=k$. In the first version of MV, a weight of all classifiers is considered the same (Nordmann and Pham 1999).

\section{Procedures}

To separate vuggy and non-vuggy zones in different depths, a binary 0 and 1 coding system is used.
Classification is performed in two stages: first, efficiency of method in each individual well for detecting vuggy zones is examined separately, and secondly generalization capability of the method in testing wells is investigated. As a result of generalization stage, there can be observed five probably different classification results. Thus, some zones are classified as vuggy zones, while the others are recognized as non-vuggy zones. At the end of the study, the results of this stage are fused using MV data fusion technique. Comparing final results with core results revealed that a combination of a 2 PLs data, Parzen classification and MV were the best approach for detecting vuggy and non-vuggy zones.

The procedure is shown by the diagram in "Appendix".

\section{Significance of the proposed method}

Optimum mother wavelets in six study wells are selected and shown in Table 2, in which bior 3.1 was selected as optimum mother wavelet in five out of six wells. Each signal is decomposed into two parts, the first part called approximation $\left(\mathrm{CA}_{n}\right)$,

Table 2 Optimum mother wavelets for decomposition PLs in six study wells

\begin{tabular}{lllllll}
\hline Well no. & W1 & W2 & W3 & W4 & W5 & W6 \\
\hline Optimum mother wavelet & bior3.1 & bior3.1 & bior3.1 & bior3.1 & bior3.1 & bior3.3 \\
\hline
\end{tabular}

CAI
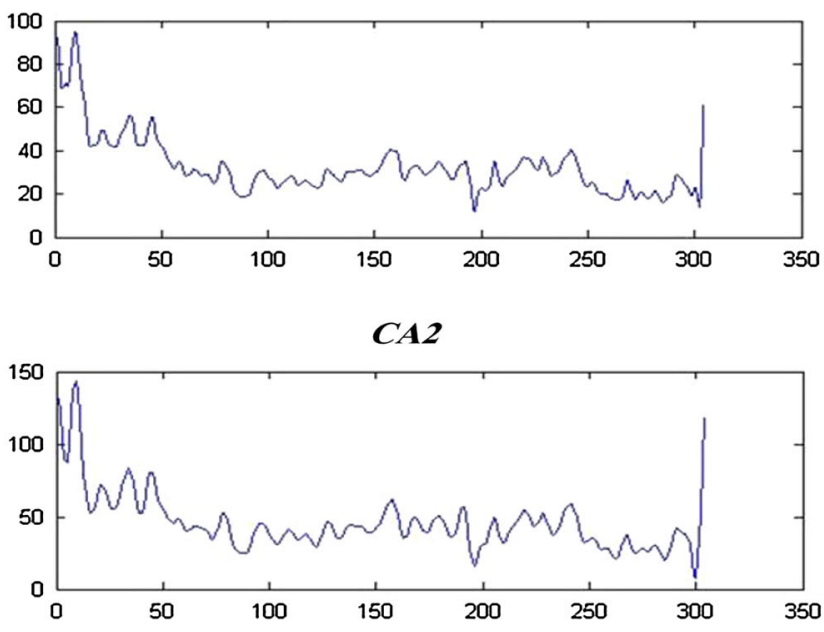

CA3

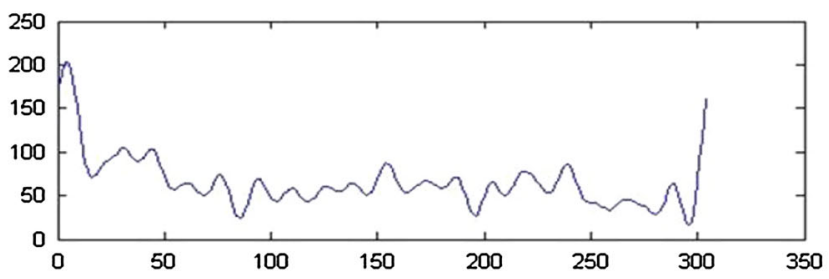

CD1
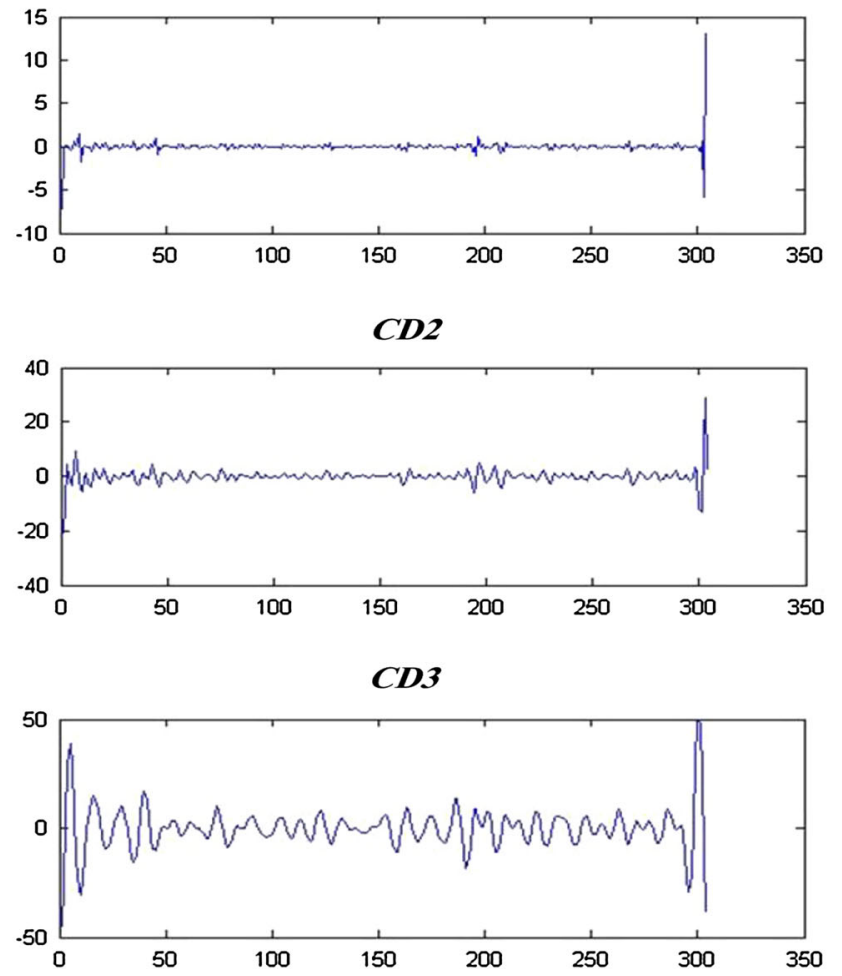

Fig. 1 Decomposition of signal to three approximates (CA1-CA3) and three details (CD1-CD3) by wavelet (in Abbreviations) 
Table 3 Results of classification in six study wells

\begin{tabular}{lllllll}
\hline & \multicolumn{2}{l}{ Well name } & & & \\
\cline { 2 - 6 } & w1 & w2 & w3 & w4 & w5 & w6 \\
\hline Accuracy of classification (\%) & 0.83 & 0.85 & 0.66 & 0.98 & 0.85 \\
Optimum $h$ & 0.078 & 0.078 & 0.03 & 0.078 & 0.078 \\
\hline
\end{tabular}

Table 4 Results of multi-well analysis

\begin{tabular}{|c|c|c|c|c|c|c|}
\hline \multirow[t]{2}{*}{ Test } & \multicolumn{6}{|c|}{ Train } \\
\hline & W1 & W2 & W3 & W4 & W5 & W6 \\
\hline W1 & & 0.83 & 0.51 & 0.66 & 0.54 & 0.64 \\
\hline W2 & 0.67 & & 0.51 & 0.59 & 0.52 & 0.58 \\
\hline W3 & 0.98 & 0.98 & & 0.95 & 0.86 & 0.95 \\
\hline W4 & 0.83 & 0.9 & 0.54 & & 0.57 & 0.74 \\
\hline W5 & 0.98 & 0.99 & 0.58 & 0.9 & & 0.92 \\
\hline W6 & 0.89 & 0.92 & 0.54 & 0.75 & 0.59 & \\
\hline
\end{tabular}

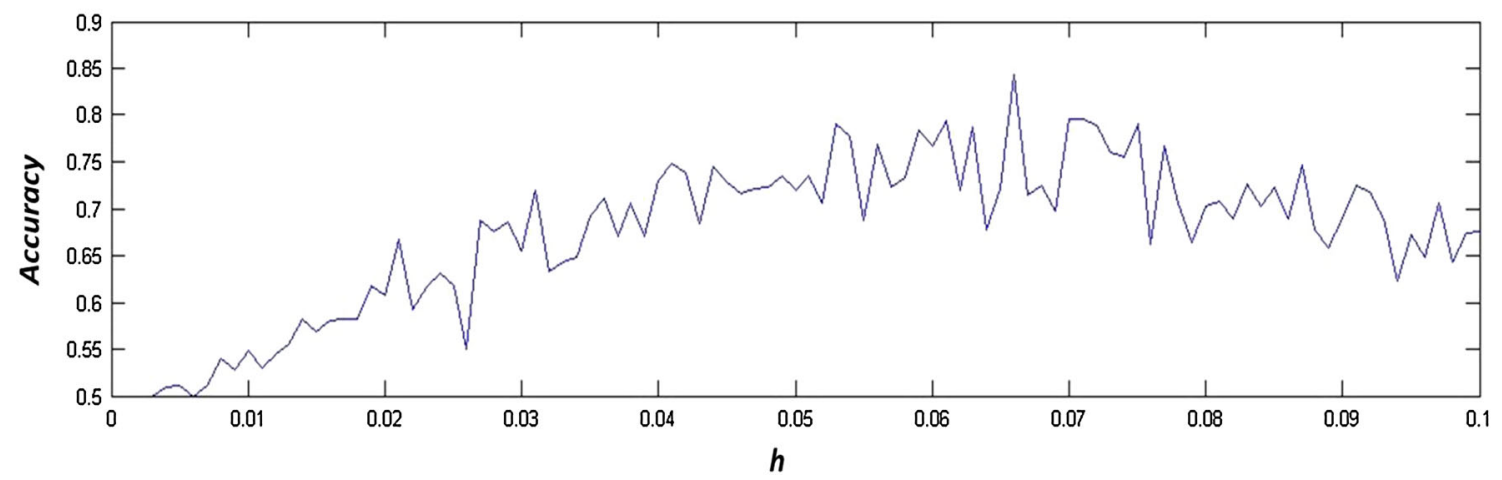

Fig. 2 Optimizing $h$ (Parzen window) when wells 1 and 3 are considered as the test and train wells, respectively

which is more similar to the initial signal; and the second part is details $\left(\mathrm{CD}_{\mathrm{n}}\right)$, which explains details of the decomposed signal. Therefore, in the case of three level decomposition:

$C A 1$ is approximate in first decomposition of signal.

$C D 1$ is detail in first decomposition of signal.

$C A 2$ is approximate in second decomposition of signal.

$C D 2$ is detail in second decomposition of signal.

$C A 3$ is approximate in third decomposition of signal.

$C D 3$ is detail in third decomposition of signal.

An example of decomposition of signal by wavelet is illustrated in Fig. 1.

According to the results, Parzen and $\mathrm{CA}_{2}$ are considered to be the best classifier and best frequency band for vuggy zone detection. Moreover, it can be seen that the average accuracy of the classification is about $82 \%$, the accuracy of detection of vuggy zone and non-vuggy zone are about 66 and $98 \%$, respectively (see Table 3). The optimum $h$ value related to Parzen classifier is also given in a separate row (see Fig. 2).
Table 4 presents the concluded results of detecting vuggy zone in multi-well stage. As the table shows, the total accuracy varies between 52 and $98 \%$ (average $75.5 \%)$.

\section{Results of data fusion}

As a result of different training wells in multi-well classification stage, there are several outputs for a depth. Therefore, one single final decision should be made about the class of the given depth.

Since all the results of a depth are as vuggy zone or nonvuggy zone, decision is very easy and the results of all methods are the same. Figure 3 illustrates a graphical comparison between identified vuggy zones and non-vuggy zones using the proposed approach together with the actual data resulted from cores investigation in six studied wells. 
Fig. 3 Good agreement

between the model results and actual vuggy and non-vuggy

zones in well no $1,4,6$
Fig. 4 Good agreement between the model results and actual vuggy and non-vuggy zones in well no 1, 4, 6 before and after MV data fusion
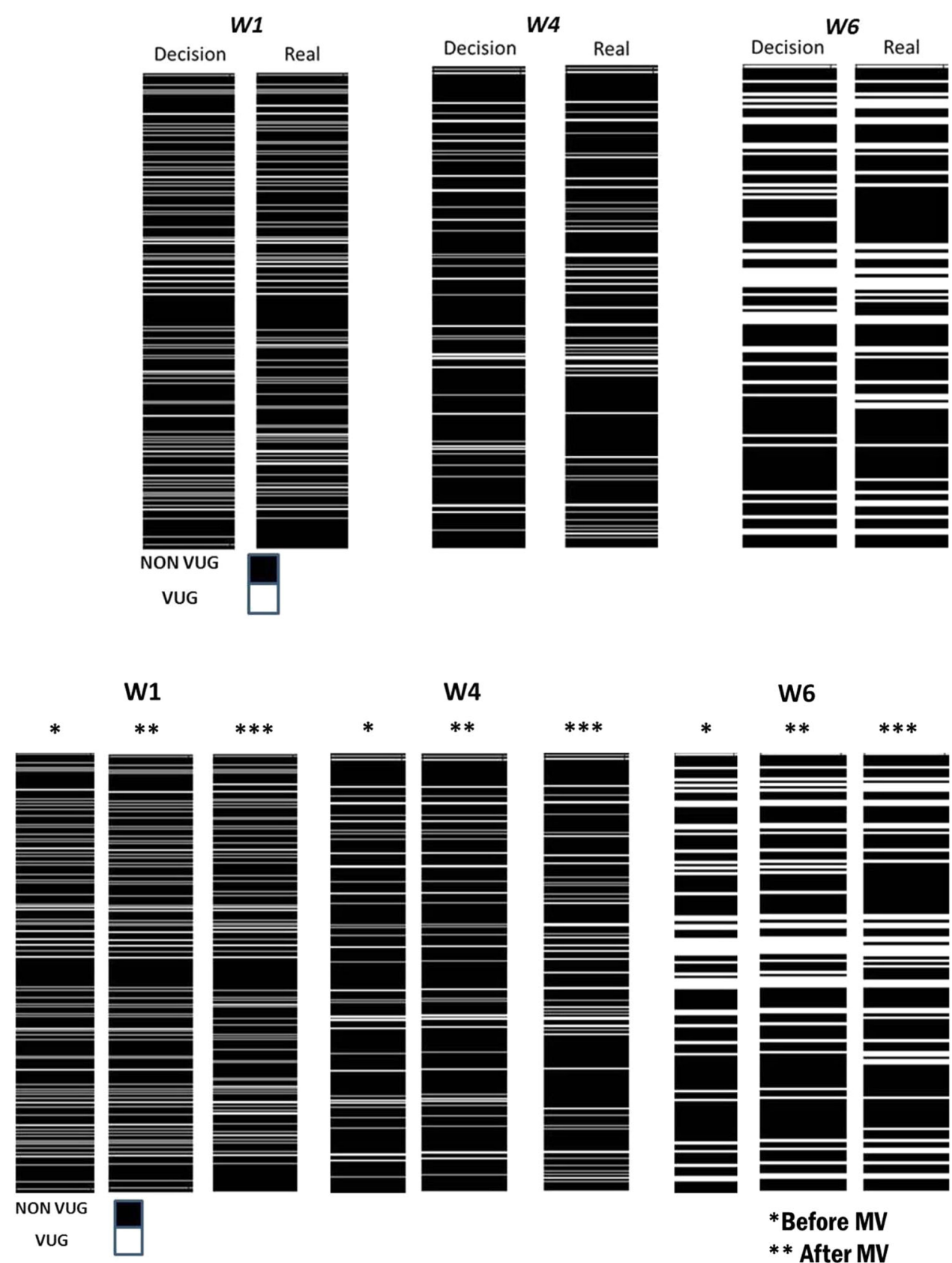

Table 5 Comparison of Parzen classification accuracy before and after MV data fusion

\begin{tabular}{llrrrr}
\hline Well number & 1 & 2 & 3 & 4 & 5 \\
\hline Accuracy before data fusion (average of five analyses) (\%) & 88 & 93 & 55 & 79 & 62 \\
Accuracy after MV data fusion (\%) & 93 & 96 & 88 & 86 & 77 \\
Accuracy improvement (\%) & +5 & +3 & +33 & +7 & +14 \\
\hline
\end{tabular}

A comparison between accuracy of Parzen classification before and after data fusion using MV is shown in Fig. 4 and Table 5. The results show that the accuracy of the classification is improved by increasing the number of training wells and quality of the input data. The accuracy of vuggy zones detection in well 5 is the least, whereas in five other wells, it is the best. As the Fig. 3 depicts, errors often occur at the margins of vuggy and non-vuggy zones. 


\section{Conclusion}

To discriminate vuggy zones from non-vuggy zones, a new combined Parzen-wavelet-data fusion methodology was presented. The proposed algorithm includes wavelet technique to reduce noises from the original petrophysical logs and Parzen classifier to classify each depth into vuggy and non-vuggy zones before and after application of wavelet transform. This approach was applied to the data of six wells selected from two different carbonate reservoirs. It was proved that de-noised data can considerably improve the accuracy of the Parzen classification and the approach is
Open Access This article is distributed under the terms of the Creative Commons Attribution 4.0 International License (http://creativecommons.org/licenses/by/4.0/), which permits unrestricted use, distribution, and reproduction in any medium, provided you give appropriate credit to the original author(s) and the source, provide a link to the Creative Commons license, and indicate if changes were made.

\section{Appendix}

- Diagram of the methodology in this study, respectively:

1. Position of signal processing in the process of analysis of signal (wavelet is one of method of signal processing).

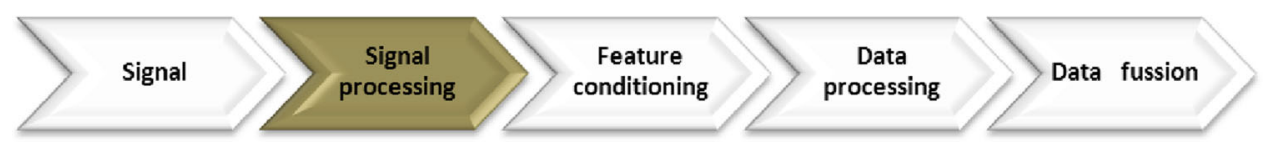

2. Position of data processing in studying of each signal

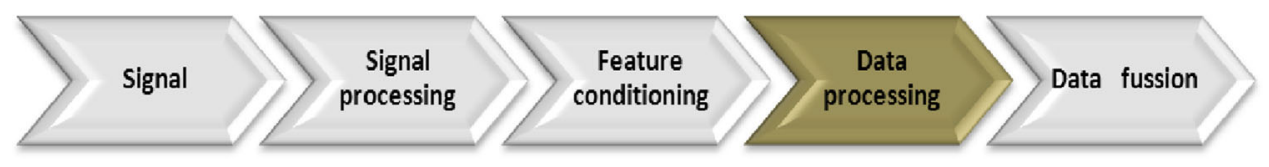

absolutely efficient in carbonate formations. The algorithm can identify vuggy zones with an acceptable accuracy (around $76 \%$ ) in generalization step. The accuracy of this analysis is dependent on two factors; the first, is distribution of vuggy porosity in different wells, and the second factor is the proportion of vuggy data to non-vuggy zones in each well. The accuracy of the proposed algorithm decreases where vuggy zones are dominant (Fig. 3). In contrast, when the proportion of vuggy to non-vuggy zones approaches one, total accuracy increases. Similarly, the accuracy of vuggy zones detection goes up. Finally, it was demonstrated that MV technique is able to improve the classification accuracy by fusing the results of more than one train well. It increases the accuracy from an average of $75.8 \%$ before data fusion to an average of $88.7 \%$ after data fusion.

Acknowledgments The authors would like to express their sincere thanks to the Exploration Directorate of National Iranian Oil Company (NIOC) for their assistance in providing the information, and for their technical input to this work. Also, Mr. Pedram Masoudi is thanked for his comments that improved the quality of this article.
3. Data processing have two branches that the procedure in this paper is shown in this diagram:

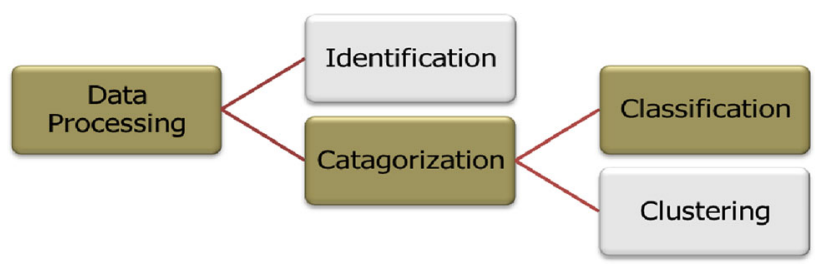

4. Classification in the data processing derived to three branches:

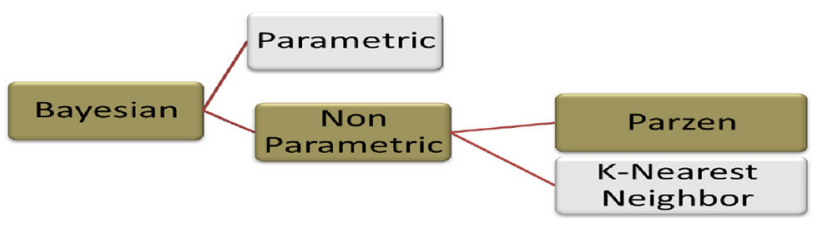


5. Parzen classifier is a method based on the Bayes theory:

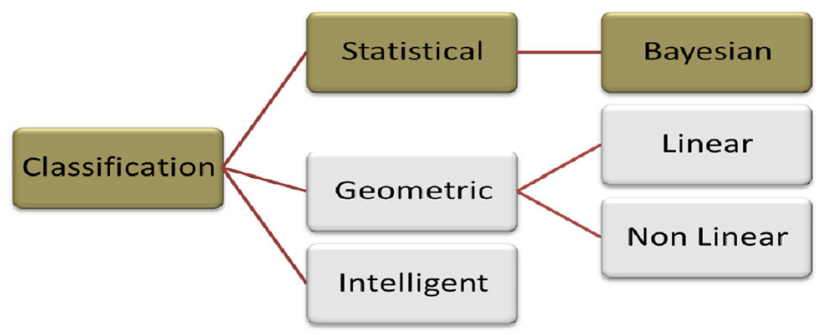

6. Last processing in each log (majority voting is simplest method in data fusion):

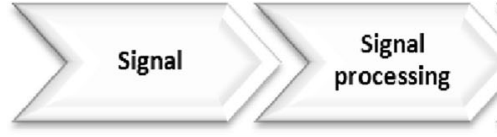

\section{References}

Aguilera R (2008) Effect of fracture dip and fracture tortuosity on petrophysical evaluation of naturally fractured reservoirs. In: Canadian international petroleum conference

Aguilera RF, Aguilera R (2004) A triple porosity model for petrophysical analysis of naturally fractured reservoirs. Petrophysics 45(2):157-166

Akram AH, Gherryo YS, Ali SM, Thabt MS, Serban A (2010) Dynamic behavior of a fissured dual-carbonate reservoir modeled with DFN. SPE 127783

Asgarinezhad Y, Tokhmechi B, Kamkar rouhani A, Sherkati S, Kavousi K (2014) A combined Parzen-wavelet approach for detection of vuggy zones in fractured carbonate reservoirs using petrophysical logs. J Petrol Sci Eng. doi:10.1016/j.petrol.2014. 04.016

Ghosh K, Ng YS, Srinivasan R (2010) Evaluation of decision fusion strategies for effective collaboration among heterogeneous fault diagnostic methods. Comput Chem Eng 35(2):342-355

Gomaa N, Al-Alyak A, Ouzzane D, Saif O, Okuyiga M, Allen D, Rose D, Ramamoorthy R, Bize E (2006) Case study of permeability, vug quantification, and rock typing in a complex carbonate. SPE 102888

Mengual JF, Recinos LM, Ho ES, FG (2000) Formation evaluation in outhern mexico's low-porosity fractured carbonate rocks using imaging and nmr tools. SPWI, A $41^{*}$ annual logging symposium, June 4-7
Hurley NF, Zimmermann RA, Pantoja D (1998) Quantification of vuggy porosity in a dolomite reservoir from borehole images and core, Dagger Draw field, New Mexico, SPE 49323

Lucia FG (1983) Petrophysical parameters estimated from visual descriptions of carbonate rocks: a field classification of carbonate pore space. J Petrol Technol 35(3):629-637

Mollajan A, Asgarinezhad Y, Tokhmechi B, Sherkati S (2014) A comparative study of two data-driven methods in detection of vuggy zones: a case study from a carbonate reservoir, west of Iran. Carbonates Evaporites. doi:10.1007/s13146-014-0201-x

Nordmann L, Pham H (1999) Weighted voting systems. In: Reliability, IEEE transactions on 48.1, pp 42-49. ISSN: 0018-9529

Pairoys F, Al-Zoukani A, Keskin A, Akbar M (2012) Electrical response of a vuggy rock model at different frequencies, SPE61399

Perez-Rosales C, Mercado-Diaz A, Cruz-Hernandez J, Islas-Juarez R (2002) Electric resistivity of vuggy fractured media. SPE 74340

Pinous O, Zellou AM, Robunson G, Royer T, Svikhnushin N, Borisenok D, Blank A (2007) Continuous fracture modeling of a carbonate reservoir in west Siberia, SPE 103284

Tang H, Toomy N, Meddaugh S (2009) Successful carbonate well log facies prediction using an artificial neural network method: Wafra Maastrichtian reservoir, partitioned neutral zone (PNZ), Saudi Arabia and Kuwait. SPE 123988

Towle G (1962) An analysis of the formation resistivity factorporosity relationship of some assumed pore geometries. In: Paper C presented at third annual meeting of SPWLA, Houston 